\title{
POSTURAL TREATMENT OF CHILDREN WITH A PARTIAL THORACIC STOMACH ('HIATUS HERNIA')
}

BY

\author{
I. J. CARRÉ* \\ From the Department of Child Health and Paediatrics, University of Birmingham and the Children's Hospital, Birmingham
}

(RECEIVED FOR PUBLICATION APRIL 4, 1960)

Considerable debate centres round the best way of treating children affected with a small partial thoracic stomach ('hiatus hernia' or 'short oesophagus') uncomplicated by an oesophageal stricture. Two diametrically opposed views exist. On the one hand there are those workers who subscribe to a conservative regimen of management. Others, in the belief that the disorder is analogous to the hiatus hernia of adults, advocate surgical procedures aimed primarily at replacing and retaining the stomach wholly within the abdomen.

The following report records the long-term results achieved with conservative postural methods of treatment. The value of such therapy has been assessed by comparing the progress of treated children with the expected outcome as deduced from the natural history of the disorder (Carré, 1959). The treatment of children with a partial thoracic stomach complicated by an oesophageal stricture is not considered.

\section{Method}

Definition of Abnormality. The following review is restricted to patients shown radiologically to have part of the stomach protruding through the oesophageal hiatus. In every instance the gastrooesophageal junction has been situated within the thorax at the upper limit of the intrathoracic gastric loculus. Patients with only gastro-oesophageal incompetence have not been considered.

Assessment of Clinical Progress. Clinical progress has been determined objectively. The same classification of symptoms has been employed as used in the study of the natural history (Carré, 1959), namely:

Frequent: If vomiting and/or difficulty in swallowing solid food was noted to occur daily or at least on alternate days in children taking a normal diet for age. The routine use of a mashed diet occasioned by a child's difficulty in swallowing solids has been

* Present address: The Department of Child Health, Institute of Clinical Science, Grosvenor Road, Belfast 12. interpreted as implying the existence of frequent symptoms despite the fact that the child on its mashed diet might have been having little or no vomiting or dysphagia.

Moderate: If vomiting and/or difficulty in swallowing solid food was noted to occur on an average of less than three times weekly but at least monthly in a child taking a normal diet for age.

Minimal: If vomiting and/or dysphagia were absent or occurred on average less than once a month in a child taking a normal diet for age.

Type of Patient Considered. In the study of the natural history (Carré, 1959) it was concluded that untreated clinically affected patients could be divided into the following relatively distinct clinical groups:

\begin{tabular}{|c|c|c|c|}
\hline Group & $\begin{array}{l}\text { Change in Symp- } \\
\text { tomatology on } \\
\text { Weaning to } \\
\text { Mixed Diet }\end{array}$ & Prognosis & $\begin{array}{l}\text { Clinically } \\
\text { Affected } \\
\text { Patients } \\
(\%)\end{array}$ \\
\hline I & $\begin{array}{l}\text { No symptoms } \\
\text { or improved }\end{array}$ & $\begin{array}{l}\text { Benign course. Major- } \\
\text { ity free of symptoms } \\
\text { by } 2 \text { years: }\end{array}$ & $60-65$ \\
\hline Survivors $_{\text {II }}$ & $\begin{array}{l}\text { No improve- } \\
\text { ment or worse }\end{array}$ & $\begin{array}{l}\text { (a) Prolonged clinical } \\
\text { course with 'moder-; } \\
\text { ate' or 'frequent' } \\
\text { vomiting and / or } \\
\text { dysphagia common- } \\
\text { ly persisting to at } \\
\text { least } 4 \text { years of age; } \\
\text { no oeso phageal } \\
\text { stricture; } \\
\text { (b) Symptoma tology } \\
\text { and progress depen- } \\
\text { dent on presence } \\
\text { of an oesophageal } \\
\text { stricture }\end{array}$ & 5 \\
\hline Deaths & & $\begin{array}{l}\text { In the absence of an } \\
\text { oesophageal stricture } \\
\text { death likely to occur } \\
\text { during infancy from } \\
\text { combination of } \\
\text { marasmus, bio- } \\
\text { chemical distur- } \\
\text { bances and infection }\end{array}$ & -0 \\
\hline
\end{tabular}

Because of the naturally occurring variation in clinical progress exhibited by individual patients, consideration of results has been restricted to the following two groups of patients whose progress in the absence of treatment could be forecast reliably. 
Group A. All patients in whom a partial thoracic stomach had been radiologically confirmed by 3 months of age were included. Since clinically affected children progress in a similar manner during the early weeks of life irrespective of the eventual outcome (Carré, 1957), it is apparent that all clinical types would be correctly represented in such a group. Thus, in the absence of beneficial treatment about one-third of these patients would be likely to pursue a protracted clinical course (Groups IIa and b of Natural History Study: Carré, 1959).

Group B. This group comprised patients who were between 6 months and 2 years of age when started on postural treatment and who were not improved clinically when weaned on to a solid diet; no patient had a proven oesophageal stricture when first seen. (Group II patients of Natural History Study: Carré, 1959.) In the absence of beneficial therapy almost all these children could therefore expect to suffer from troublesome symptoms until at least 4 years of age with about one in six developing an oesophageal stricture.

\section{Group A Patients}

During the period of study all infant patients whose partial thoracic stomach had been radio- logically confirmed by 3 months of age were treated routinely by posture from the time of diagnosis; none of these patients received any form of surgical treatment before the age of $3 \frac{1}{2}$ years. In view of the therapeutic policy adopted this group therefore represents a consecutive and unselected series of patients all of whom were started on postural treatment within the first 3 months of life. All surviving patients have been followed up to at least 4 years of age.

Although some patients had oesophageal narrowing on fluoroscopy, none had a proven oesophageal stricture at the time of starting treatment. All suffered from symptoms of 'frequent' severity when started on treatment. No child showed signs of a commencing spontaneous symptomatic improvement.

Patients given 'Adequate' Postural Therapy. In this section only those patients have been considered whose treatment fulfilled the following requirements: (a) Patients were kept in a sitting posture with the trunk inclined at $60^{\circ}$ or more with the horizontal. Posturing of a lesser degree occasionally employed during the early stages of this study was found to be therapeutically ineffective (Fig. 1). As it was impossible to maintain this degree of propping

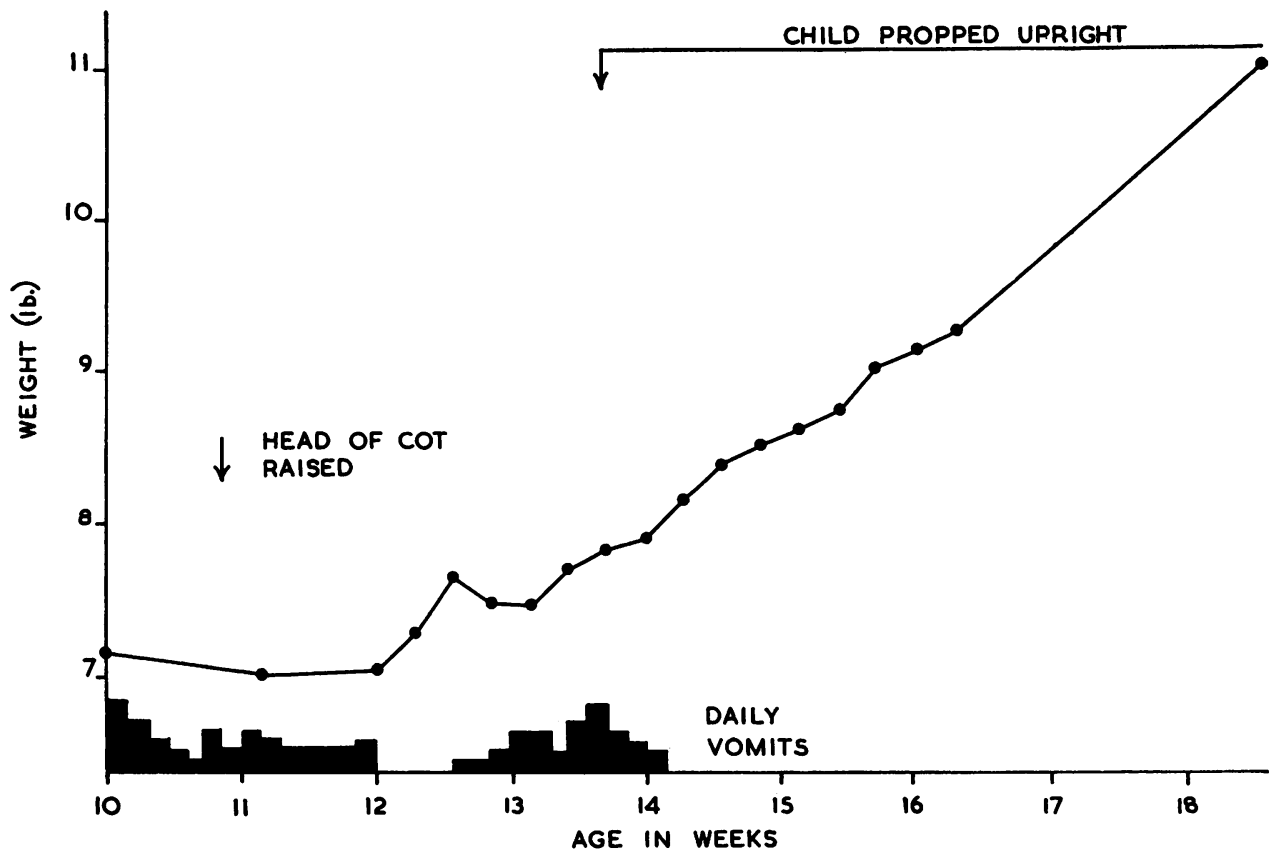

FIG. 1.-At 10 weeks this infant weighed only $10 \mathrm{oz}$. more than his birth weight. The patient was treated by propping with one pillow and raising the head of the cot on 10-in. blocks. No significant improvement was noted over a period of three weeks. Subsequent to nursing in an erect posture vomiting ceased and a rapid gain in weight was recorded. This patient was $7 \frac{1}{2}$ years old when last seen. There had been no recurrence of vomiting. 
TABLE 1

PROGRESS OF 34 PATIENTS STARTED ON 'ADEQUATE' POSTURAL TREATMENT BEFORE 3 MONTHS OF AGE

\begin{tabular}{|c|c|c|c|c|c|c|c|c|}
\hline \multirow{3}{*}{$\begin{array}{l}\text { Case } \\
\text { No. }\end{array}$} & \multicolumn{2}{|c|}{$\begin{array}{c}\text { 'Adequate' } \\
\text { Postural Treatment }\end{array}$} & \multirow{3}{*}{$\begin{array}{c}\text { Supplementary } \\
\text { Treatment }\end{array}$} & \multirow{2}{*}{\multicolumn{3}{|c|}{$\frac{\text { Clinical Progress }}{\text { Severity of Symptoms and Age }}$}} & \multirow{2}{*}{\multicolumn{2}{|c|}{$\begin{array}{c}\text { Age at } \\
\text { Last Review }\end{array}$}} \\
\hline & \multirow{2}{*}{$\begin{array}{l}\text { Age } \\
\text { Started } \\
\text { (weeks) }\end{array}$} & \multirow{2}{*}{$\begin{array}{c}\text { Age } \\
\text { Discontinued } \\
\text { (months) }\end{array}$} & & & & & & \\
\hline & & & & Frequent & Moderate & Minimal & Yrs & Mths \\
\hline $\begin{array}{l}16 \\
80^{*} \\
81 \\
83 \\
87 \\
88 \\
90 \\
91 \\
97 \\
98 \\
99 \\
102 \\
103 \\
106 \dagger\end{array}$ & $\begin{array}{r}1 \\
7 \\
2 \\
2 \\
12 \\
2 \\
6 \\
2 \\
2 \\
12 \\
2 \\
2 \\
3 \\
2\end{array}$ & $\begin{array}{r}12 \\
30 \\
10 \\
14 \\
12 \\
8 \\
9 \\
7 \\
70 \\
12 \\
8 \\
14 \\
4 \\
18\end{array}$ & $\begin{array}{l}\text { - } \\
\text { Thickened feeds } \\
\text { Thickened feeds } \\
\text { Alkali } \\
\text { - } \\
\text { - } \\
\text { Atropine, alkali }\end{array}$ & 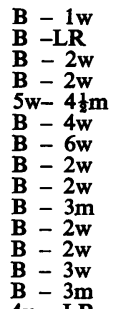 & $\begin{array}{c}- \\
= \\
- \\
4 w-7 w \\
- \\
2 w-5 m \\
2 w-8 w \\
3 m-4 m \\
2 w-6 w \\
2 w-12 m \\
3 w-5 w \\
3 m-4 y\end{array}$ & $\begin{array}{r}1 w-L R \\
\text { - } \\
2 w-L R \\
2 w-L R \\
4 \frac{1}{2 m-L R} \\
7 w-L R \\
6 w-L R \\
5 \mathrm{~m}-\mathrm{LR} \\
8 w-L R \\
4 \mathrm{~m}-\mathrm{LR} \\
6 \mathrm{w}-\mathrm{LR} \\
12 \mathrm{~m}-\mathrm{LR} \\
5 \mathrm{w}-\mathrm{LR} \\
-\end{array}$ & $\begin{array}{l}7 \\
6 \\
7 \\
6 \\
5 \\
4 \\
5 \\
6 \\
7 \\
7 \\
4 \\
5 \\
6\end{array}$ & $\begin{array}{r}5 \\
8 \\
0 \\
5 \\
6 \\
0 \\
9 \\
7 \\
1 \\
\mathbf{6} \\
\mathbf{1 1} \\
\mathbf{6} \\
\mathbf{1}\end{array}$ \\
\hline $\begin{array}{l}112 \\
113 \\
114\end{array}$ & $\begin{array}{r}10 \\
2 \\
6\end{array}$ & $\begin{array}{r}7 \\
6 \\
21\end{array}$ & - & $\begin{array}{l}4 y-L R \\
B-5 m \\
B-2 w \\
B-6 w\end{array}$ & $\begin{array}{c}- \\
2 w-4 w \\
6 w-5 m\end{array}$ & $\begin{array}{l}5 \mathrm{~m}-\mathrm{LR} \\
4 \mathrm{w}-\mathrm{LR} \\
5 \mathrm{~m}-8 \mathrm{~m}\end{array}$ & $\begin{array}{l}7 \\
6 \\
4\end{array}$ & $\begin{array}{l}1 \\
3 \\
0\end{array}$ \\
\hline $\begin{array}{l}115 \\
121 \\
123 \\
124 \\
126 \\
127\end{array}$ & $\begin{array}{l}3 \\
2 \\
4 \\
9 \\
7 \\
7 \\
12\end{array}$ & $\begin{array}{l}16 \\
15 \\
12 \\
3 \\
16 \\
23\end{array}$ & $\begin{array}{l}\text { - } \\
\text { Alkali, thickened feeds } \\
\text { Thickened feeds } \\
\text { Thickened feeds }\end{array}$ & $\begin{array}{l}\mathbf{B}-3 \mathbf{w} \\
\mathbf{B}-2 \mathbf{w} \\
\mathbf{B}-2 \mathrm{~m} \\
\mathbf{B}-2 \mathbf{w} \\
\mathbf{B}-8 \mathbf{w} \\
\mathbf{B}-6 \mathbf{m}\end{array}$ & $\begin{array}{l}8 m-12 m \\
2 w-4 w \\
2 m-5 m \\
2 w-6 w \\
6 m-13 m\end{array}$ & $\begin{array}{r}12 \mathrm{~m}-\mathrm{LR} \\
3 \mathrm{w}-\mathrm{LR} \\
4 \mathrm{w}-\mathrm{LR} \\
5 \mathrm{~m}-\mathrm{LR} \\
6 \mathrm{w}-\mathrm{LR} \\
8 \mathrm{w}-\mathrm{LR} \\
13 \mathrm{~m}-\mathrm{LR}\end{array}$ & $\begin{array}{l}6 \\
5 \\
6 \\
5 \\
4 \\
6 \\
7\end{array}$ & $\begin{array}{r}5 \\
10 \\
0 \\
11 \\
5 \\
0 \\
4\end{array}$ \\
\hline $\begin{array}{l}139 \\
144 \\
146 \\
147 \\
148 \\
149 \\
154 \\
156 \\
158 \\
159\end{array}$ & $\begin{array}{l}9 \text { days } \\
9 \text { days } \\
12 \\
2 \\
4 \\
12 \\
3 \\
2 \\
7 \\
4\end{array}$ & $\begin{array}{r}2 \\
6 \\
24 \\
6 \\
6 \\
14 \\
9 \\
12 \\
5 \\
10\end{array}$ & $\begin{array}{c}\text { - } \\
\text { Thickened feeds } \\
= \\
- \\
\text { Thickened feeds, }\end{array}$ & $\begin{array}{l}B-2 w \\
B-2 w \\
B-5 m \\
1 w-3 w \\
B-5 w \\
1 w-14 w \\
B-6 w \\
B-4 w \\
5 w-9 w \\
B-7 m\end{array}$ & $\begin{array}{l}- \\
5 \mathrm{~m}-20 \mathrm{~m} \\
3 \mathrm{w}-3 \mathrm{~m} \\
5 \mathrm{w}-3 \mathrm{~m} \\
-\bar{w}-12 \mathrm{w} \\
4 \mathrm{w}-9 \mathrm{~m} \\
9 \mathrm{w}-3 \mathrm{~m} \\
7 \mathrm{~m}-8 \mathrm{~m}\end{array}$ & $\begin{array}{r}2 \mathrm{w}-\mathrm{LR} \\
2 \mathrm{w}-\mathbf{L R} \\
20 \mathrm{~m}-\mathrm{LR} \\
3 \mathrm{~m}-\mathrm{LR} \\
3 \mathrm{~m}-\mathbf{L R} \\
14 \mathrm{w}-\mathrm{LR} \\
12 \mathrm{w}-\mathbf{L R} \\
9 \mathrm{~m}-\mathrm{LR} \\
3 \mathrm{~m}-\mathbf{L R} \\
8 \mathrm{~m}-\mathbf{L R}\end{array}$ & $\begin{array}{l}5 \\
5 \\
5 \\
4 \\
5 \\
5 \\
4 \\
4 \\
4 \\
4\end{array}$ & $\begin{array}{l}3 \\
1 \\
4 \\
5 \\
0 \\
3 \\
9 \\
7 \\
1 \\
1\end{array}$ \\
\hline 168 & 1 & 8 & Thickened feeds & $B-3 w$ & $3 w-7 w$ & 7w-LR & 5 & 3 \\
\hline
\end{tabular}

* Only two vomits per year from 2 years, but food finely cut up because of dysphagia.

† Developed an oesophageal stricture; surgical repair of 'hiatus hernia' when 6 years old.

Abbreviations: $\mathrm{d}=$ days $\mathrm{w}=$ weeks $\mathrm{m}=$ months $\mathrm{y}=$ years $\mathbf{L R}=$ last review $\mathrm{B}=$ birth

without the use of some form of chair or supportive harness only those infants have been included who were kept propped up by means of some such appliance.* (b) Posturing was maintained continuously day and night up to the age of 1 year, or if symptoms had subsided before, until a minimum of six weeks complete freedom of symptoms had been recorded.

Treatment Given in Addition to Posture. The routine policy throughout was first to try the effect of posture without altering the feeding regimen in any way. If progress was considered unsatisfactory postural treatment was augmented by thickening

\footnotetext{
* Initially many methods were devised, but the plaster chair described by Hill (1953) has been used routinely in the treatment of patients during the latter part of this study. Other postural appliances have been described by Davies (1952) and Rosenweig (1954).
}

the feeds. $\dagger$ In fact, only eight of 34 infants were given thickened feeds in addition to postural therapy. Treatment was further supplemented in two of these eight by the administration of alkali which was also prescribed for two others in the group.

Results. Thirty-four infants were treated by adequate sustained posture as defined above. All were kept under regular out-patient supervision at a special follow-up clinic throughout the period of treatment. The clinical progress of these infants is summarized in Table 1.

$\uparrow$ Methods used to thicken feeds:

(i) Benger's Food-one teaspoonful to 2 oz. of milk feed.

(ii) Cornflour-one tablespoonful to a pint of milk feed.

(iii) Carob-seed flour, marketed under the name of 'nestargel' by the Nestle Company-half to one teaspoonful to $12 \mathrm{oz}$. of feed $(0 \cdot 5-1 \%$ of powder to each feed).

These thickened feeds were given by feeding bottle using a teat with a large hole. Additional thickening, if desired, was obtained by merely increasing the concentration of the thickening agent. 
Only four of these 34 infants suffered from either 'moderate' or 'frequent' symptoms beyond 12 months and only two beyond 2 years of age. One of these latter children (Case 80) had vomited only two to three times a year from 2 years of age until last seen when 6 years 8 months old. During this period, however, she had continued to have difficulty with swallowing and required to have solid food finely cut up. Examination by barium swallow and fluoroscopy at her last attendance showed no evidence of oesophageal narrowing. The other child (Case 106) showed no improvement with treatment and developed an oesophageal stricture. A surgical repair of the 'hiatus hernia' when she was 6 years old did not produce any significant benefit and when seen one year later she still complained of frequent dysphagia and vomiting.

These results compare favourably with the expected outcome of a similar group of untreated patients (Carré, 1959). Without treatment, it is probable that at 12 months of age about 22 and at 2 years about 15 patients would have been troubled with symptoms of either 'moderate' or 'frequent' severity. Of these, 11 would still have been vomiting more than once a month on average at 4 years with one or two having developed an oesophageal stricture. One other patient might have died in infancy.

The speed of response to treatment was variable. In some patients improvement was dramatic while symptoms in others abated only slowly over a period of months. The speed of response may be determined from the time interval between the institution of therapy and the onset of symptoms of 'minimal' severity. This period was less than two weeks in 12 patients. In a further 12 this interval varied between two weeks and three months. In eight patients the response to treatment was gradual with intervals varying from three to 17 months between the commencement of treatment and the onset of 'minimal' symptoms. Two patients failed to respond. Confirmatory observations were recorded in 20 other similarly treated patients excluded from the present review because of an inadequate follow-up. Seven of these 20 patients had virtually ceased vomiting within two weeks and another eight within three months of starting treatment. The prompt beneficial response which may follow the institution of postural treatment is illustrated by Case 121 (Fig. 2).

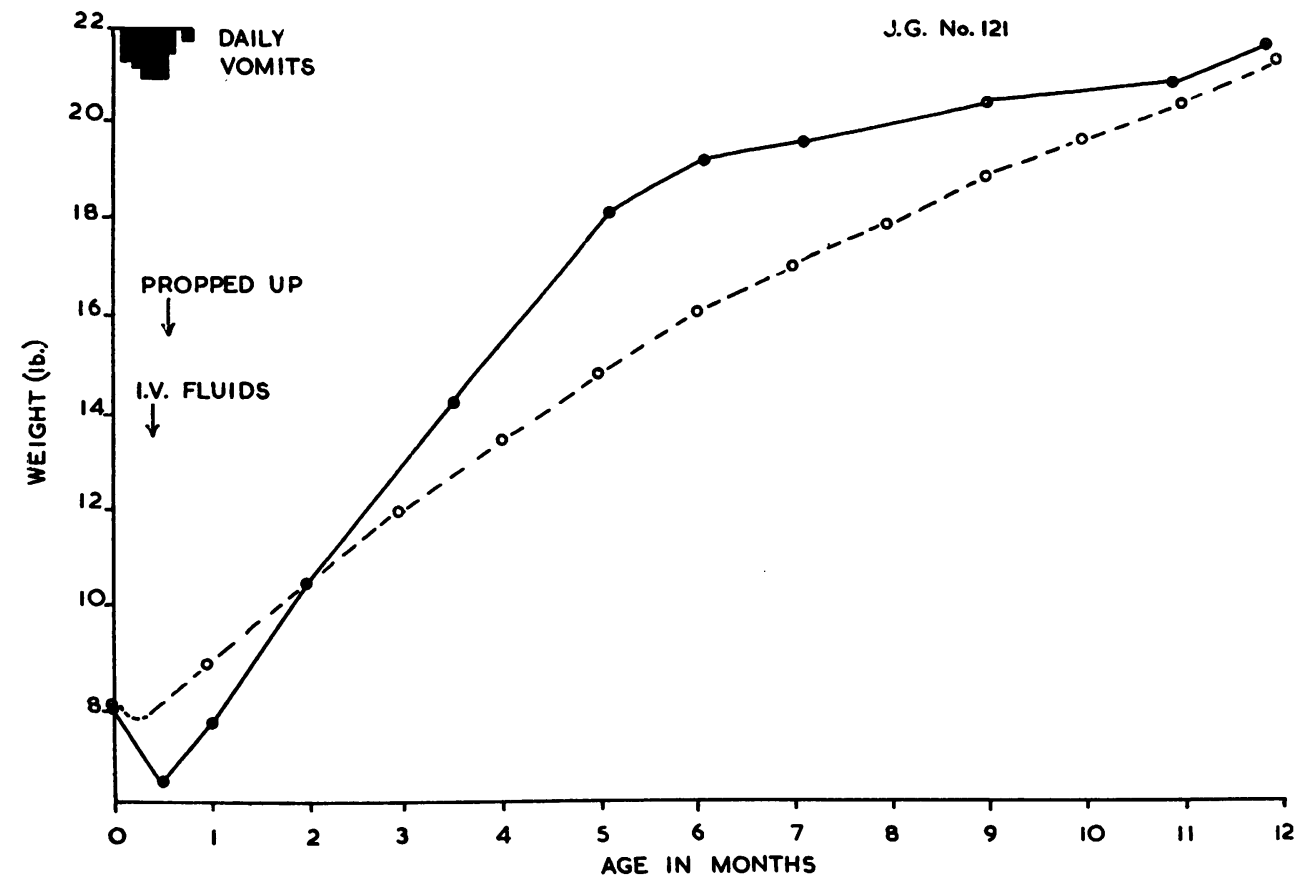

FIG. 2.-The progress of this child illustrates the prompt symptomatic response which may follow the institution of adequate postural treatment in early infancy. This infant commenced vomiting at 3 days. When 2 weeks old she weighed 1 lb. 12 oz. less than her birth weight. Following rehydration with intravenous fluids and treatment by nursing in an erect posture vomiting ceased dramatically and concurrently her weight rose steadily. She was last seen at 6 years of age; there had been no recurrence of symptoms, but she still had a demonstrable partial thoracic stomach when examined by barium swallow and fluoroscopy. Weight - - - 
TABLE 2

PROGRESS OF 15 PATIENTS DIAGNOSED BEFORE 3 MONTHS OF AGE BUT GIVEN 'INADEQUATE' POSTURAL TREATMENT

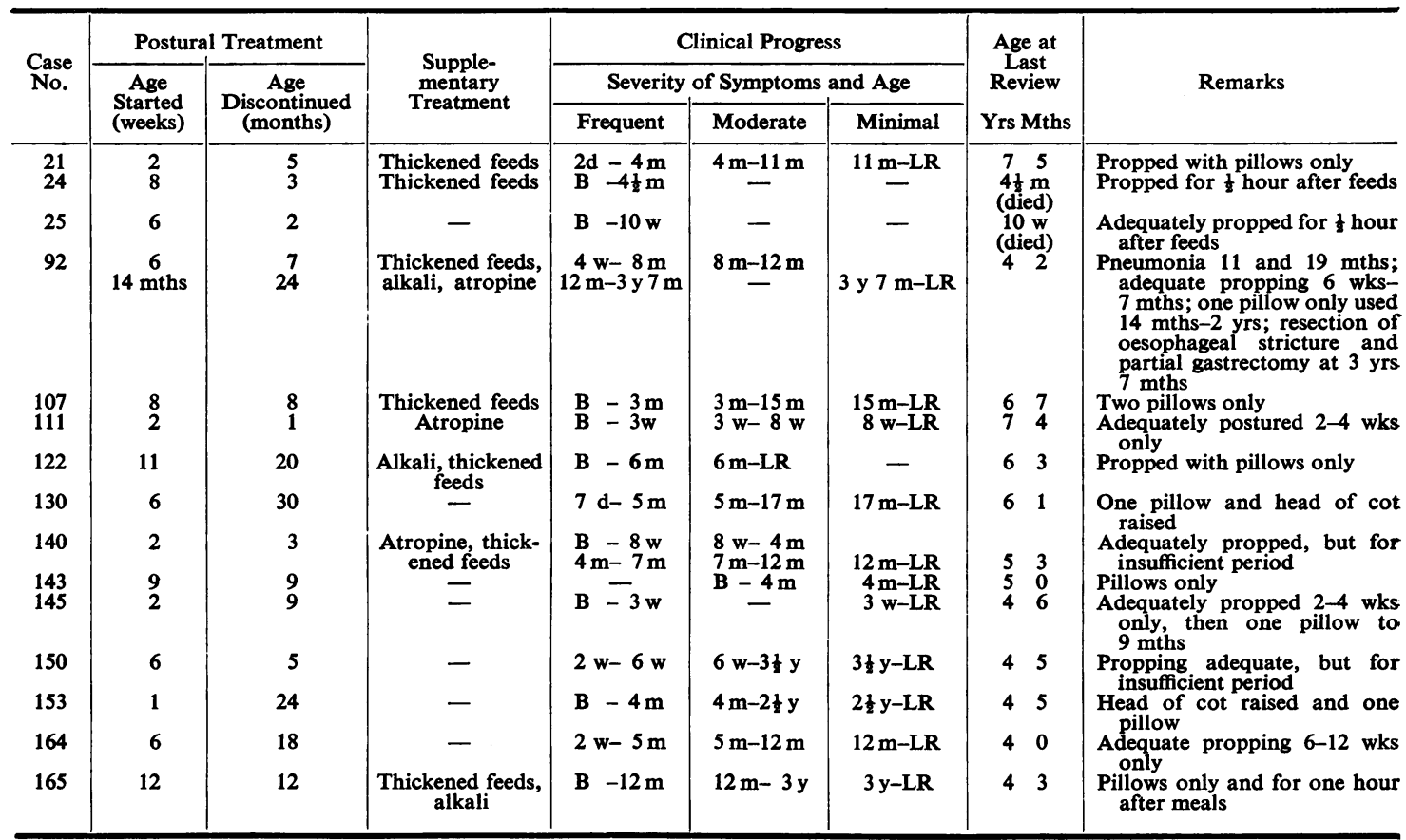

Abbreviations as in Table 1.

Patients Given 'Inadequate' Postural Treatment. For the purpose of comparison a summary is included of the progress of 15 children given 'inadequate' treatment. Postural treatment has been judged as 'inadequate' for the following reasons. Pillows only were used to posture seven patients, while in eight instances propping though adequate in degree, was either employed intermittently or continued for an insufficient period (Table 2).

There was an additional important difference between the two groups. These patients, in contrast to those already discussed, were not kept under regular out-patient supervision. In other respects they were exactly comparable to those considered in the previous section with the exception that one patient (Case 143) had symptoms of only 'moderate' severity at the time of commencing treatment.

Results. Eight children were well by 2 years. Two patients died in early infancy. One child developed an oesophageal stricture. The remaining four children suffered from symptoms of 'moderate' severity beyond 2 years of age; one of these still had 'moderate' symptoms at 4 years.
These results are not dissimilar to the expected outcome should none of these children have been treated by posture. For, in the absence of treatment eight or nine would probably have been well by 2 years of age. Of the others, possibly one might have died and another developed an oesophageal stricture. The remaining four or five children would probably have suffered from symptoms of at least 'moderate' severity up to 4 years of age and longer.

\section{Group B}

The greater strength and activity of these older patients made it infinitely less practical to effect a comparable degree of sustained propping as quoted for Group A patients. It has been necessary, therefore, to adopt much less strict criteria of treatment. Patients have been included where a genuine attempt had been made to keep them propped throughout the night and during daytime rest periods.

Children considered in this survey have been treated by posture for either a minimum period of nine months, or a period extending for six weeks beyond the onset of 'minimal' symptoms should 
this have occurred before nine months treatment had been given.

No child was subjected to any surgical procedure other than oesophagoscopy during the nine months of postural treatment.

All patients considered were 4 years of age or more at the time of their last review.

Results. There were only nine patients whose symptomatology and treatment conformed with the above conditions. Alkali was given as supplementary treatment to five patients; two of these were given atropine as well. The clinical progress of these patients is summarized in Table 3 .

Three patients developed an oesophageal stricture; one other child suffered from symptoms of 'moderate' severity until the age of 6 years 11 months. The remaining five children had only 'minimal' symptoms at 4 years of age; in four 'minimal' symptoms had dated from 2 years or younger. If untreated it is probable that only one or two of the nine patients would have shown much improvement by 4 years of age.

The response to treatment appeared to be unrelated to the age of commencing treatment. Of four whose treatment started before 12 months of age, two developed an oesophageal stricture while two were well at 4 years; of five commencing treatment between 12 and 24 months, one developed a stricture, one suffered from 'moderate' symptoms until almost 7 years and three were clinically well at 4 years.
Fig. 3 shows the progress of one patient who responded to conservative therapy.

\section{Complications of Postural Treatment}

The only complications observed which could in any way be attributed to postural therapy were occasional sore buttocks, usually encountered at the start of treatment, and a flattening of the head similar to that described by Craig (1953).

Flattening of Head. The following brief review was undertaken with the object of determining more precisely the relationship of a flattened head to postural treatment. In the absence of anatomical measurements a child has been regarded as having a 'flat' head if the alteration in head shape was sufficiently obvious to cause comment. Three groups of patient are considered:

1. Children who were kept sitting up at $60^{\circ}$ or more throughout each 24 hours for a minimum period of one month and who were followed-up for at least six months from the start of treatment.

2. Children who were postured either intermittently or for less than one month, or in whom the degree of propping was less than that stated for Group 1.

3. Patients given no postural treatment and who were between 6 months and 2 years of age when seen.

As shown in Table 4 a flattened head was only

TABLE 3

PROGRESS OF NINE PATIENTS BETWEEN 6 AND 24 MONTHS WHEN STARTED ON POSTURAL THERAPY

\begin{tabular}{|c|c|c|c|c|c|c|c|c|}
\hline \multirow{3}{*}{$\begin{array}{l}\text { Case } \\
\text { No. }\end{array}$} & \multirow{3}{*}{$\begin{array}{l}\text { Age of } \\
\text { Starting } \\
\text { Postural } \\
\text { Treatment } \\
\text { (months) }\end{array}$} & \multirow{3}{*}{$\begin{array}{l}\text { Supple- } \\
\text { mentary } \\
\text { Treatment }\end{array}$} & \multicolumn{3}{|c|}{ Clinical Progress } & \multirow{2}{*}{\multicolumn{2}{|c|}{$\begin{array}{l}\text { Age at } \\
\text { Last } \\
\text { Review }\end{array}$}} & \multirow{3}{*}{ Remarks } \\
\hline & & & \multicolumn{3}{|c|}{ Severity of Symptoms and Age } & & & \\
\hline & & & Frequent & Moderate & Minimal & Yrs & Mths & \\
\hline 55 & 20 & - & $\begin{array}{l}\mathrm{B}-20 \mathrm{~m} \\
2 \text { y } 10 \mathrm{~m}-\end{array}$ & $\begin{array}{l}20 \mathrm{~m}-22 \mathrm{~m} \\
3 \text { y } 6 \mathrm{~m}- \\
6 \text { y } 11 \mathrm{~m}\end{array}$ & $\begin{array}{l}22 \mathrm{~m}- \\
2 \text { y } 10 \mathrm{~m} \\
6 \text { y } 11 \mathrm{~m}-\end{array}$ & 8 & 4 & $\begin{array}{l}\text { Postural treatment discontinued } 2 \frac{1}{2} \text { yrs; } \\
\text { recommenced } 3 \text { yrs } 4 \text { mths (two pil- } \\
\text { lows) until } 6 \text { yrs }\end{array}$ \\
\hline $\begin{array}{r}62 \\
79 \\
86 \\
101\end{array}$ & $\begin{array}{l}17 \\
8 \frac{1}{2} \\
18 \\
18\end{array}$ & $\begin{array}{l}\text { Alkali, atropine } \\
\text { Alkali } \\
\text { Alkali } \\
\text { - }\end{array}$ & $\begin{array}{l}\text { B-12 m } \\
\text { B-8 } \frac{1}{2} \mathrm{~m} \\
9 \mathrm{~m}-18 \mathrm{~m} \\
\text { B-LR }\end{array}$ & $\begin{array}{l}12 \mathrm{~m}-17 \mathrm{~m} \\
8 \frac{1}{2} \mathrm{~m}-18 \mathrm{~m} \\
18 \mathrm{~m}-20 \mathrm{~m}\end{array}$ & $\begin{array}{l}17 \text { m-LR } \\
18 \mathrm{~m}-\mathrm{LR} \\
20 \mathrm{~m}-\mathrm{LR} \\
\text { - }\end{array}$ & $\begin{array}{l}4 \\
7 \\
4 \\
4\end{array}$ & $\begin{array}{l}0 \\
6 \\
1 \\
9\end{array}$ & $\begin{array}{l}\text { Propping discontinued } 2 \frac{1}{2} \text { yrs } \\
\text { Propping discontinued } 3 \frac{1}{\frac{1}{2}} \text { yrs } \\
\text { Propping discontinued } 2 \frac{1}{2} \text { yrs } \\
\text { Propped } 18 \text { mths-2 } 2 \frac{1}{2} \text { yrs; oesophageal } \\
\text { stricture } 2 \text { yrs; repair of 'hiatus } \\
\text { hernia' at } 4 \text { yrs } 7 \text { mths; good immedi- }\end{array}$ \\
\hline $\begin{array}{l}110 \\
119\end{array}$ & $\begin{array}{r}6 \\
10\end{array}$ & Alkali, atropine & $\underset{\text { B-LR }}{\text { B-18 m }}$ & $18 \mathrm{~m}-2$ y $4 \mathrm{~m}$ & 2 y 4 m-LR & $\begin{array}{l}4 \\
5\end{array}$ & $\begin{array}{l}3 \\
3\end{array}$ & $\begin{array}{l}\text { Propping discontinued } 2 \text { yrs } \\
\text { Propping discontinued } 2 \text { yrs; } \\
\text { oesophageal stricture } 21 \mathrm{mths}\end{array}$ \\
\hline 129 & 8 & Alkali & $\begin{array}{l}\text { B-18 m } \\
18 \frac{1}{2} \mathrm{~m}- \\
3 \text { y } 6 \mathrm{~m}\end{array}$ & $18 \mathrm{~m}-18 \frac{1}{2} \mathrm{~m}$ & 3 y $\overline{6 \mathrm{~m}-L R}$ & 4 & 1 & $\begin{array}{l}\text { Treated by posture for } 10 \mathrm{mths} \\
\text { Oesophageal stricture } 16 \mathrm{mths} \text {; repair } \\
\text { of 'hiatus hernia' } 18 \mathrm{mths} \text {; no im- } \\
\text { provement; resection of stricture and } \\
\text { oesophago-gastrostomy } 3 \frac{1}{2} \text { yrs; im- } \\
\text { proved; died } 4 \text { yrs } 1 \mathrm{mth} \text { from neuro- } \\
\text { blastoma }\end{array}$ \\
\hline 160 & 14 & - & B-18 m & $18 \mathrm{~m}-2 \mathrm{y}$ & 2 y-LR & 4 & 4 & Postured for $12 \mathrm{mths}$ \\
\hline
\end{tabular}




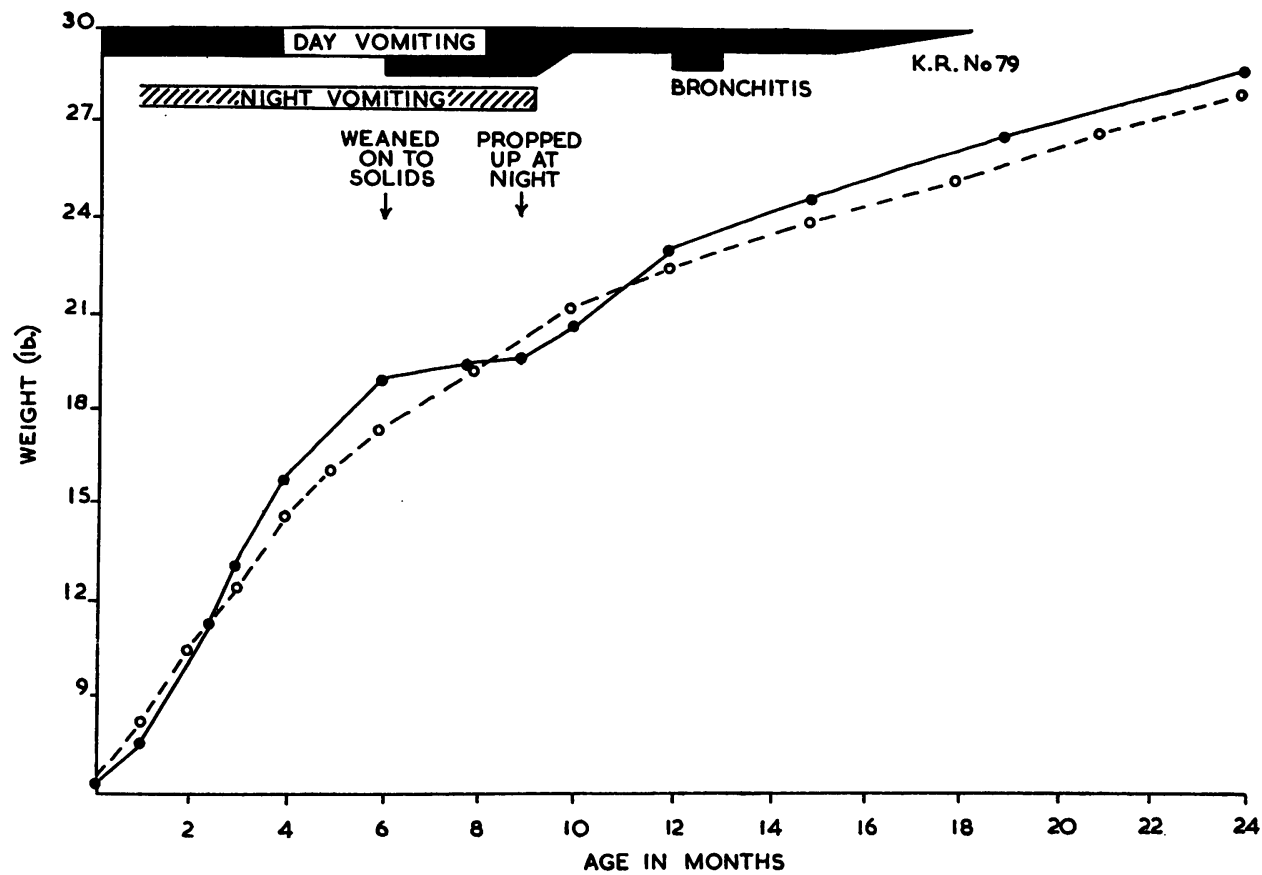

FIG. 3.-Despite vomiting from birth this infant gained weight satisfactorily until 6 months. During the following three months vomiting increased and no weight gain was recorded. No solid food was retained. From the time of starting postural treatment at $8 \frac{1}{2}$ months, vomiting at night, which had been a notable feature, ceased and dysphagia and day vomiting gradually subsided over a period of nine months. Except for an occasional vomit associated with respiratory infections this child remained free of symptoms up to his last review at $7 \frac{1}{2}$ years.

noted among children of Group 1; all were less than 3 months old when started on treatment. Eight of the 13 children who developed a 'flat' head were girls. Birth weights ranged from $4 \mathrm{lb}$. $14 \mathrm{oz}$. to $9 \mathrm{lb}$. $4 \mathrm{oz}$. with an average of $6 \mathrm{lb}$. $15 \mathrm{oz}$. Two children were noted as having developed a 'flat' head within one month of starting treatment.

\section{Discussion}

Value and Limitations of Postural Therapy. Postural treatment for the purpose of this review has been regarded as 'adequate' only if it entailed

TABLE 4

RELATIONSHIP OF POSTURAL TREATMENT TO ALTERATIONS IN SHAPE OF HEAD

\begin{tabular}{|c|c|c|c|}
\hline \multirow{2}{*}{$\begin{array}{l}\text { Age on Starting } \\
\text { Postural Treatment } \\
\text { (months) }\end{array}$} & \multicolumn{3}{|c|}{ Number of Patients } \\
\hline & Group 1 & Group 2 & Group 3 \\
\hline $\begin{array}{l}0-1 \\
1-2 \\
2-3\end{array}$ & $\left.\begin{array}{r}31(7) \\
11(3) \\
7(2)\end{array}\right\} 49(13)$ & $\left.\begin{array}{l}6(0) \\
6(0) \\
3(0)\end{array}\right\} 15(0)$ & $11(0)$ \\
\hline$>3$ & $22(0)$ & $12(0)$ & \\
\hline
\end{tabular}

Figures in brackets indicate number of patients with a 'flat' head. For definition of groups 1, 2 and 3, see text. keeping infants propped at $60^{\circ}$ or more throughout the 24 hours. These requirements were originally formulated largely on the basis of theoretical reasoning during the early stages of this study in 1951.

By 1950 the aetiological importance of gastrooesophageal reflux in the development of oesophagitis, ulceration and ultimately stricture formation in adult patients had been established (Tileston, 1906; Winkelstein, 1935; Dick and Hurst, 1942; Johnstone, 1943; Allison, Johnstone and Royce, 1943). Similar oesophageal changes noted in some children with a partial thoracic stomach appeared to have an identical aetiology as free gastrooesophageal reflux was a frequently associated radiological feature. The damaging effect of gastric juice, hydrochloric acid and pepsin on the oesophageal mucosa had been demonstrated experimentally by Friedenwald, Feldman and Zinn (1928), Selye (1938) and Ferguson, Sanchez-Palomera, Sako, Clatworthy, Toon and Wangensteen (1950). There was, therefore, good evidence for supposing that the greatest danger to patients with gastrooesophageal incompetence lay in the regurgitation of unbuffered and undiluted gastric juice. 
Lelong, Aimé, Aubin and Bernard (1939) reported that infants with a 'brachyoesophage' were improved if nursed propped up after feeds. These observations were later confirmed by Wyllie and Field (1946), Nicod (1948) and Roviralta (1949). It seemed logical to postulate that the assumption of an erect posture by invoking the aid of gravity lessened the amount of gastro-oesophageal reflux in these infants which secondarily resulted in an amelioration of symptoms. On the basis of this reasoning it seemed particularly important that any such posturing should not be confined to short periods during the day or after feeds, but should be maintained throughout the night when the protective effect of food in buffering and diluting gastric contents was non-operative. Continued posturing throughout the 24 hours was therefore adopted as an essential requisite of 'adequate' therapy.

In addition to keeping patients propped up throughout the 24 hours, it soon became apparent that to be therapeutically effective posturing had to be of such a degree that patients were maintained in a sitting position (Fig. 1). It was found impossible to maintain this degree of propping without the use of some form of supportive harness or chair and for this reason postural treatment which did not include the use of some such appliance has been regarded as 'inadequate.'

No evidence has been obtained from this study favouring a relaxation of these measures. On the contrary, the results achieved have demonstrated that prolonged sustained propping in a sitting posture is essential if maximum benefit is to be obtained from this form of therapy. Whereas encouraging long-term results were recorded in the group of infants started on 'adequate' treatment by 3 months of age, a second comparable group given 'inadequate' therapy compared unfavourably. In fact, the ultimate prognosis of these latter children did not appear to have been materially influenced by therapy. These results also emphasize the importance of out-patient supervision. There is little doubt that an important factor contributing to the adequacy of treatment in the former group was the fact that patients were kept under regular outpatient observation. Though difficult of accurate evaluation, two features appeared to affect adversely the long-term response to treatment, namely maternal inadequacy, often aggravated by poor social conditions, and recurrent upper respiratory tract infections causing temporary exacerbations of vomiting.

It is possible to define two distinct clinical groups among infant patients based on their response to postural therapy. Of patients started on 'adequate' sustained postural treatment by 3 months of age approximately two-thirds had virtually ceased vomiting within three months of starting treatment. By contrast, improvement in the remaining onethird was slow with troublesome symptoms persisting for many months. The relative proportions of these two groups, namely two-thirds and onethird, are identical to those of the two clinical categories recognizable among untreated infant patients, i.e. Groups I and II of the natural history study (Carré, 1959). This similarity in distribution suggests that the patients who responded promptly to treatment were in fact precisely those who, if untreated, would have undergone a spontaneous clinical cure by 2 years of age (Group I). Whereas, those whose improvement was slow and protracted were probably patients who, in the absence of treatment, would have suffered from troublesome symptoms to 4 years and older, with a few developing an oesophageal stricture as a complication (Groups IIa and b). Yet, with prolonged postural therapy eight of the 10 latter patients became virtually symptom free by 2 years of age; vomiting in four of these did not cease until after nine months of continuous therapy. The absence of a rapid symptomatic response should not be interpreted therefore as an indication per se for abandoning postural treatment.

Postural treatment when first started in late infancy or early childhood was not accompanied by such encouraging results as noted when treatment was started during the first months of life. Nevertheless, it seems that about half of the older patients are likely to benefit from postural treatment. There are two probable reasons why treatment should be less effective when first instituted at this age. The pathological changes in the lower oesophagus are more likely to be irreversible and, secondly, sustained adequate posturing is more difficult to achieve because of these patients' greater activity and strength.

Having regard to the recorded results and analytical precautions adopted, it is concluded that postural treatment is of considerable value in the management of infants with a partial thoracic stomach uncomplicated by an oesophageal stricture. To be maximally effective, however, treatment must be commenced as early in infancy as possible, and patients should be propped at $60^{\circ}$ or more throughout the 24 hours. Treatment should be continued for as long as 12 months should troublesome symptoms persist; in refractory cases little additional benefit is likely to result from more prolonged treatment. In those patients who respond it is advisable to continue with treatment for a further 
six weeks after the virtual cessation of all symptoms.

It must be appreciated that the effectiveness of postural treatment in this study has been determined solely by reference to clinical disturbances. Although of undoubted clinical benefit, there is no evidence that postural treatment influences the radiological 'cure' rate (Carré and Astley, 1960).

Postural treatment can only be regarded as routinely applicable if at the same time it can be asserted that no permanent undesirable ill effects are likely to accrue. Craig (1953) has recorded a flattening of the head in two infants with a 'hiatus hernia' treated by posture-an observation subsequently confirmed by Davies (1953). Thirteen similar instances have been noted among 98 patients treated by posture. All 13 children who developed a 'flat' head had been started on treatment before the age of 3 months and had been maintained continuously in a sitting posture for at least one month. These latter patients represented about one-quarter of the children so treated (Table 4). Not a single instance was seen among children treated by intermittent or lesser degrees of propping, among children over 3 months of age when started on treatment nor among untreated patients. The relationship of a 'flat' head to postural therapy is further emphasized by the findings in two sets of identical twins. One set was started on 'adequate' postural treatment at 10 days of age; both infants developed a 'flat' head. Of the other set of twins one infant was treated by posture from 7 weeks; the other received no postural treatment. The twin treated by posture developed a 'flat' head, whereas the other did not.

It might be thought that the skull of a premature baby would be softer and more malleable than that of a full-term infant and that as a result premature babies would be particularly liable to develop alterations in head shape. However, it was not possible to demonstrate any relationship between birth weight and the development of a 'flat' head in this series.

It is apparent that the 'flat' head seen in certain children with a partial thoracic stomach arises secondarily to the maintenance of an erect posture during the early months of infancy. That this abnormality may develop relatively quickly is illustrated by the two patients in this series who had developed a 'flat' head within one month of starting treatment. As these 'flat' headed children grow older the alteration in head shape becomes progressively less noticeable and it is probable, though not certain, that the abnormality eventually resolves completely.
That the propping up of small babies might result in eventual maldevelopment of the spine is often of justifiable concern to parents, and Braid (1953) has questioned whether prolonged treatment in an erect position might not interfere with normal pelvic growth. Though specifically looked for, no evidence of either spinal or pelvic maldevelopment has been noted among children in this series.

The introduction of thickened feeds was of great supplementary value in the few infants slow to respond to posture alone. Alkali and atropine derivatives were given so infrequently and sporadically that no reliable assessment of their therapeutic value is possible on the basis of this study. That these agents may have contributed to the symptomatic recovery of the few patients given these medicaments cannot be discounted. It may possibly be of significance that three of the four children whose treatment first started between 6 and 24 months of age and who either developed an oesophageal stricture or were still troubled with vomiting at 4 years of age had not been given alkali. On the other hand, of the five comparable patients whose symptoms at 4 years were 'minimal', four had been given alkali as supplementary treatment. In any case, until such time as unequivocal evidence to the contrary has been produced there seems to be, on at least theoretical reasoning, sufficient justification for the use of alkali as supplementary therapy.

Comparison of Published Results. Although only sufficient experience has been gained from this study to justify conclusions on the value and limitations of postural therapy, the published results of both medical and surgical treatment are briefly reviewed for the purpose of comparison. Only information relating to the treatment of children with a proven partial thoracic stomach uncomplicated by an oesophageal stricture is considered. Unfortunately, a strict comparison of published results with those of this study is largely impossible because of the frequent omission of essential data on methods and duration of treatment, length of follow-up, criteria of assessment and even more important the age and type of child treated. Moreover, most reported series include both medically and surgically treated patients. This raises an additional difficulty as it is seldom clear why patients were chosen to receive either one or other form of therapy. Because of the inevitable selection involved the results quoted in such reports need to be evaluated with considerable caution.

Good clinical results following conservative postural treatment have been claimed by Lelong, Aimé and Aubin (1941), Roviralta (1952), Fox and 
Hunter (1954), Swyer (1955) and Burke (1959). Unfortunately, the information provided is insufficient to permit of comparison with the observations of this study. A very limited comparison has been possible with the observations of Masse and Bader (1957). For the most part patients seen by these authors were first treated conservatively and only if the immediate response to treatment was poor were they then subjected to operation. Analysis of their results shows that of children with a gastrooesophageal abnormality corresponding to the partial thoracic stomach of this study, 38 started on a similar medical regimen of treatment within the first three months of life; $22(58 \%)$ responded sufficiently promptly for operative treatment to be withheld (Masse, 1959, personal communication). These observations agree with those of the present review in which it was noted that among 54 comparable patients $35 \%$ became virtually symptomfree within two weeks and $72 \%$ within three months of starting postural therapy.

In contrast, unsatisfactory results from medical treatment are quoted by Forshall (1955) and Thomsen (1955). A critical evaluation of the information provided by these authors suggests how such a contrary opinion to that of this study has come about.

On the basis of experience gained in treating nine patients by postural methods Forshall (1955) expresses disagreement with the suggestion that many ultimately do well with conservative therapy. Details of the postural methods and duration of treatment are not stated nor is the patient's age on starting treatment. However, it would appear that at least five of the nine children were over 2 years of age and two had an oesophageal stricture. As illustrated in this study such patients represent precisely those who would not be expected, and indeed do not, respond well to medical treatment. It is important that these limited observations should be viewed in their correct perspective. Referring as they do to a particular type of patient it is clear that they should not be interpreted as representative of the results of medical treatment as applied to all children with a partial thoracic stomach.

Analysis of Thomsen's (1955) data shows that 24 patients were treated by postural methods for varying periods. The use of a harness or chair is not mentioned and it is probable that the degree of propping was less than that used in the present study. Two patients died from causes unrelated to the gastro-oesophageal abnormality. Of the remaining 22 only 12 were considered to have made a satisfactory response to conservative treatment. Eleven were diagnosed before 3 months of age and, although by no means certain, it is assumed that their treatment will have dated from the time of diagnosis. With postural treatment as defined and applied in the present study 10 or possibly all would have been expected to respond. In fact only six became symptom free; their ages at the time of their last review varied from 15 months to 4 years. The other five children were considered to have failed to respond to treatment and were subjected to operation. However, consideration of the histories of these five patients indicates that in three at least postural treatment was maintained for less than six weeks. Had treatment been continued longer it is likely that these patients would also have responded. For, of comparable patients studied in this review about one-quarter showed little improvement until after three months continuous propping. The remaining 11 conservatively treated children in Thomsen's series were over 3 months of age when started on treatment. Such a group will include a high proportion of relatively severely affected children only about one half of whom are likely to respond to conservative measures. In fact, six of the 11 improved and became symptom free. Thus, although at first sight the results quoted by this author appear less satisfactory closer scrutiny reveals no significant difference from those of the present study.

A similar divergence of opinion exists with regard to the value of surgical treatment. Forshall (1955) records in a short follow-up review that surgical repair of the 'hiatus hernia' resulted in relief of symptoms in 29 of 30 children so treated. These are excellent results, but before giving credit to the surgical procedures employed it would be of considerable moment to know the age of these children at operation and, in view of its undoubted beneficial effect, to know if postural treatment was used to any extent either before or after operation. In any case a final assessment must await a more prolonged follow-up because of the possibility of relapse months after apparent surgical cure. In view of the therapeutic policy advocated by this author of 'operation in all cases in which the cardia is above the diaphragm' it can be assumed that most patients would have been operated on shortly after establishing the diagnosis, in which case the majority are likely to have been small infants. Should this in fact be so then the symptomatic results achieved are not notably different from those obtained in this review. Unfortunately, Forshall's encouraging results are not confirmed by other workers. Husfeldt (1953), for example, refers to the results of surgical treatment as being 'far from satisfactory'. Excluding three patients with an 
associated oesophageal stricture only 10 of 24 patients were regarded by this author as cured following a surgical repair of the 'hiatus hernia'. Allowing for differing techniques, why should this surgeon's experience differ from that of the previous author? One important factor would seem to be the type of patient treated. In Husfeldt's series about half were over 2 years of age and there is little doubt that many had irreversible pathological changes in the oesophagus. It is noteworthy that of comparable patients treated by posture in the present study about half were similarly benefited.

Relatively disappointing surgical results have also been published by Guichard, Verger and Humeau (1956), Bettex and Genton (1957) and Robb (1957).

Doubt regarding the efficacy of surgical treatment is expressed by Burke (1959) in a follow-up report on the series of patients originally reported by Waterston (1954). Of 64 surgically treated patients only 12 responded immediately with cessation of vomiting. Of the others 'improvement had sometimes begun before surgery was undertaken, but more often it was not evident until months or even years afterwards'. It should be noted, however, that 25 children in this series had an oesophageal stricture at the time of operation.

One other report dealing with the surgical treatment is that of Duhamel (1957). Excluding patients with an oesophageal stricture, 24 of this surgeon's patients had a gastro-oesophageal abnormality corresponding to the partial thoracic stomach of this study. An excellent or satisfactory response to therapy was noted in 20; four showed no improvement. Some degree of comparison is possible with the experience recorded in the present study. It is probable that most of the patients operated on had had a trial period of medical treatment beforehand in view of the therapeutic policy adopted by this author's medical colleagues (Masse and Bader). On the evidence of the present review the nine infants who were less than 6 months old when operated on by Duhamel would probably have improved over a period of months had postural treatment been continued. In fact, following operation two of the nine responded promptly, six made a slow recovery with gradual cessation of vomiting and one was not improved. These surgical results are not therefore significantly dissimilar to what would probably have occurred had postural treatment been more prolonged. On the other hand, of 15 children operated on when over 6 months of age seven made a prompt recovery, five improved slowly and three showed little clinical change. Assuming that all had troublesome symptoms at the time of operation these results reflect an improvement on those of the present study for of comparable patients only about half benefited from prolonged postural therapy.

Although considerable experience in treating children with a partial thoracic stomach has been gained during the past few years, there exists no unanimity of opinion on the relative value of therapeutic procedures. In a disorder such as the partial thoracic stomach where there is such a wide variation in the naturally occurring clinical progress of individual patients it is imperative that strict analytical precautions should be adopted when assessing the value of therapeutic measures. Failure to do this and a lack of appreciation of the natural history have been mainly responsible for the controversial views expressed. For this reason the present study is considered to have an important subsidiary value. It is suggested that similar analytical procedures might usefully be adopted by other workers when assessing the results of either conservative or surgical treatment. If this were done there seems good reason to expect that many of the divergent views at present expressed would soon be resolved.

\section{Summary}

In this study the value and limitations of postural treatment in the management of children with a partial thoracic stomach uncomplicated by an oesophageal stricture have been assessed. The clinical progress of treated patients has been compared with the expected outcome as determined from a previous study of the natural history. All patients considered were followed-up to at least 4 years of age.

It is concluded that postural treatment is of great value in the management of these patients. To obtain maximum benefit it is necessary, however, that patients be sat up at $60^{\circ}$ or more throughout the 24 hours. This degree of propping can only be maintained by using some form of supportive harness or chair. Treatment should be continued for up to 12 months should troublesome symptoms persist.

The most favourable clinical results were recorded in patients aged less than 3 months when started on treatment; 30 of 34 so treated were virtually symptom free at 1 year of age. On the other hand, only about one half of the older patients improved.

As supplementary treatment, thickened feeds were found to be of unquestionable benefit. The value of alkali could not be accurately ascertained though the available evidence suggests that this therapy is also helpful.

The only significant complication of treatment was the development of a 'flat' head in a few patients. 
This alteration in head shape was confined to children who were started on treatment when under 3 months of age and maintained continuously in a sitting posture for at least one month.

A review of the literature is included showing that although much data have been collected during the past few years there still exists no unanimity of opinion and much confusion of thought on the relative merits of different therapeutic procedures. It is submitted that a failure to employ strict analytical methods when assessing the value of therapy combined with a lack of appreciation of the natural history have been the factors mainly responsible for the controversial views expressed.

I wish to thank Professor J. M. Smellie of the University of Birmingham for much encouragement during the conduct of this study, Dr. R. Astley for the radiological diagnosis of these patients and all medical and surgical consultants at the Children's Hospital, Birmingham, who kindly allowed me to supervise the treatment of their patients.

\section{REFERENCES}

Allison, P. R., Johnstone, A. S. and Royce, G. B. (1943). Short esophagus with simple peptic ulceration. J. thorac. Surg., 12, 432.

Bettex, M. and Genton, N. (1957). Résultats éloignés du traitement chirurgical de la hernie hiatale. XVIeme Congrès de l'association des pédiatres de langue française, 4,91 .

Braid, F. (1953). Possible sequel of treating infants in the erect posture (correspondence). Brit. med. J., 2, 225.

Burke, J B. (1959). Partial thoracic stomach in childhood. Ibid., 2, 787.

Carrê, I. J. (1957). A clinical study of the partial thoracic stomach in children. M.D. Thesis, Cambridge.

- (1959). The natural history of the partial thoracic stomach ('hiatus hernia') in children. Arch. Dis. Childh., 34, 344.

and Astley, R. (1960). The fate of the partial thoracic stomach ('hiatus hernia') in children. Ibid., 35, 484.

Craig, J. (1953). Possible sequel of treating infants in the erect posture (correspondence). Brit. med. $J, 2,98$.

Davies, W. (1952). Cardio-chalasia in infancy. J. Pediat., 41, 467. (1953). Possible sequel of treating infants in the erect posture (correspondence). Brit. med. J., 2, 887.
Dick, R. C. S. and Hurst, A. (1942). Chronic peptic ulcer of the oesophagus and its association with congenitally short oesophagus and diaphragmatic hernia. Quart. J. Med., 35, 105.

Duhamel, B. (1957). Les malpositions oesophago-cardio-tubérositaires chez l'enfant. Traitement chirurgical. XVIeme congrès de l'association des pédiatres de langue française, $3,149$.

Ferguson, D. J., Sanchez-Palomera, E., Sako, Y., Clatworthy, H. W. Toon, R. W. and Wangensteen, O. H. (1950). Studies on experimental esophagitis. Surgery, 28, 1022.

Forshall, I. (1955). The cardio-oesophageal syndrome in childhood. Arch. Dis. Childh., 30, 46.

Fox, E. G. and Hunter, J. L. P. (1954). Partial thoracic stomach in childhood. J. Irish med. Ass., 34, 136.

Friedenwald, J., Feldman, M. and Zinn, W. F. (1928). Ulceration of the esophagus. Arch. intern. Med., 42, 521.

Guichard, R., Verger, P. and Humeau, A. (1956). Les syndromes cardio-tubérositaires du nourrisson vomisseur. Arch. Mal.

Hill, E. E. E. (1953). Chair for infants with gastro-oesophageal incompetence. Lancet, $2,71$.

Husfeldt, E. (1953). Hiatus hernia in infants and adults. $G t$ Ormond Str. J. (No. 6), 71.

Johnstone, A. S. (1943). Peptic ulceration of the oesophagus with partial thoracic stomach. Brit.J. Radiol., 16 (n.s.), 357.

Le!ong, M. Aimé, P. and Aubin A. (1941). Le brachy-oesophage chez le nourrisson. Presse méd., 49, 106.

-, and Bernard, J. (1939). Le brachyoesophage avec estomac partiellement thoracique. Bull. Soc. med. Hop. Paris, 55,145 .

Masse, N. P. and Bader, J. P. (1957). Les malpositions oesophagocardio-tubérositaires chez l'enfant. XVIeme congrès de l'association des pédiatres de langue française, $3,112$.

Nicod, M. (1948). Vomissements par anomalies oesophagogastriques chez le nourrisson. Praxis, 37, 745.

Robb, D. (1957). Hiatus hernia in infants and children. N.Z. med. J., 56,238

Rosenweig, J. L. (1954). Cardio-esophageal relaxation. Treatment with an inexpensive chair. J. Pediat., 44, 574.

Roviralta, E. (1949). Sur quelques causes des vomissements dits 'habituels' du nourrisson. Helv. paediat. Acta, 4, 445 .

'habituels' du nourrisson. Helv, paediat. Acta, 4, 445. Flammarion, Paris.

Selye, H. (1938). The experimental production of peptic haemorrhagic esophagitis. Canad. med. Ass. J., 39, 447.

Swyer, P. R. (1955). Partial thoracic stomach and esophageal hiatus hernia in infancy and childhood. A.M.A. Amer. J. Dis. Child., $90,421$.

Thomsen, G. (1955). Hiatus hernia in children: a radiologic-clinical study comprising 58 cases. Acta radiol. (Stockh.) (Suppl. 129), pp. $1-199$.

Tileston, W. (1906). Peptic ulcer of the oesophagus. Amer. J. med. Sci., 132, 240

Waterston, D. J. (1954). Discussion on hiatus hernia. Proc. roy. Soc. Med., 47, 536.

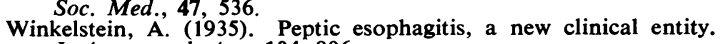

J. Amer. med. Ass., 104, 906.
Wyllie, W. G. and Field, C. E. (1946). The etiology of intermittent oesophageal regurgitation and haematemesis in infants Arch. Dis. Childh., 21, 218. 